\title{
Novel Practical Insight into Application of Platelet-Rich Plasma in Combination with Bioresorbable Silicate 45S5 Bioactive Glass for Bone Defect Repair: an Experimental Study in a Rabbit Model
}

\author{
Mohamed Tayiser Samy, Ismail Attia Shaban, Islam Foad Mandoh, Ahmed \\ Abdelbaset Ismail El-AzZaZY*
}

Department of Surgery, Faculty of Veterinary Medicine, Zagazig University, Zagazig 44511, El-Sharkia, Egypt.

\begin{abstract}
This study was aimed to verify the individual or combining effect of platelet-rich plasma $(\mathrm{PRP})$ and unique biodegradable silicate 45S5 bioactive glass (BG) scaffold on regeneration of metaphyseal tibia defect in a rabbit model. Thirty-six animals were allocated into three groups $(\mathrm{n}=12$ each). In each group, during surgery, right-sided defects were filled with BG, PRP or BG/PRP (1:1), while left-sided defects were served as a control. To visualize and trace defects healing, macroscopic, radiologic and histological examinations were performed at different time points. Bone density/radiopacity and macroscopic (defect size) values were collected and analyzed statistically. Histomorphometric quantitative analysis of H\&E stained sections to quantify the percent bone formation at 6 and 8 weeks after implantation was also performed. The gained results showed a significant increase of bone regeneration by 60 days in both $\mathrm{BG}$ and $\mathrm{BG} / \mathrm{PRP}$-groups $(\mathrm{P}<0.05$ and $\mathrm{P}<0.001$, respectively). Whereas, the healing pattern created by PRP/BG was better comparing to that of $\mathrm{BG}$ alone. We noticed unexpectedly incomplete defect closure in PRP-group by 60 days, even though and interestingly, PRP alone accelerated bone radiopacity and new osseous formation significantly only at early stages of healing period $(\mathrm{P}<0.01)$. Histomorphometric analyzed data indicated an increasing bone formation over time in all treated defects except PRP during 8 weeks. In conclusion, PRP alone does not provide an appreciated healing effect; however, in future, use of PRP combined with 45S5 BG might be clinically beneficial for proper bone regeneration as safe and appropriate biomaterial.
\end{abstract}

\footnotetext{
Editor | Kuldeep Dhama, Indian Veterinary Research Institute, Uttar Pradesh, India

Received | August 18, 2014; Revised | September 02, 2014; Accepted | September 03, 2014; Published | September 14, 2014

*Correspondence | Ahmed Abdelbaset Ismail El-Azzazy, Zagazig University, Egypt; Email: a4ismail@yahoo.co.uk

Citation | Samy MT, Shaban IA, Mandoh IF, El-Azzazy AAI (2014). Novel practical insight into application of platelet-rich plasma in combination with bioresorbable silicate 45S5 bioactive glass for bone defect repair: an Eexperimental study in a rabbit model. Adv. Anim. Vet. Sci. 2 (8): 424-432

DOI | http://dx.doi.org/10.14737/journal.aavs/2014/2.8.424.432

ISSN (Online) | 2307-8316; ISSN (Print) | 2309-3331
}

Copyright $\odot 2014$ El-Azzazy. A. A. I. et al., This is an open access article distributed under the Creative Commons Attribution License, which permits unrestricted use, distribution, and reproduction in any medium, provided the original work is properly cited.

\section{INTRODUCTION}

A lthough current surgical strategies; including autogenous grafts or alloplastic materials applied for large bone defect repair are successful in a wide range, however, they have some significant deficiencies. Particularly, limited availability with donor site morbidity in the use of autogenous grafts, and risk of disease transmission, rejection, lack of osteoinductivity and eventual graft lysis in the use of alloplastic mate- rials have been recorded (Fang et al., 2006; Almaiman et al., 2013). At this regards, biomaterials that are safe, strongly incorporate with bone tissue and much osteoinductivity are really essential as a clinical alternative to osseous grafts. Silicate bioactive glass (BG) especially 45S5 particulate (Hench, 1998) is resorbable bioactive synthetic ceramic that has both potentiality to form strong incorporation with osseous tissue and antimicrobial effect (Abdollahi et al., 2013; Rivadeneira et al., 2013). Additionally, it has been shown to lend 
greater and faster bone formation effects, through in vivo studies, when tested with other ceramics in multiple tissues (Wheeler et al., 2000; Vogel et al., 2001). Several protein- and gene- factors required during endogenous bone healing cascade, e.g., transforming growth factor- $\boldsymbol{\nabla}$, bone morphogenetic proteins and others have been approved to stimulate osteogenesis (Lieberman et al., 2002). Rich source of these factors that could be readily obtained is platelet-rich plasma (PRP) (Wang and Avila, 2007). Since, PRP could be autogenously employed; there is no risk of iatrogenic infection or immune stimulation (Marx et al., 1998; Sanchez et al., 2003). However, single (alone) or complementary (with other biomaterial) effect of PRP still needs more clarification especially through in vivo studies. For assurance, there have been multiple trials evaluating the effect of PRP merged with BG (not the type used here) on human and animals (only with oral and maxillofacial defects), nonetheless, this combination remains questionable (Demir et al., 2007; Trindade-Suedam et al., 2010; Carvalho et al., 2011; Penteado et al., 2013). Therefore, the main concept of the study outlined here was to compare the regenerative potentiality of $\mathrm{PRP}, 45 \mathrm{~S} 5 \mathrm{BG}$ or $\mathrm{BG} / \mathrm{PRP}$ in treatment of metaphyseal tibia defects in a rabbit model.

\section{MATERIALS AND METHODS}

\section{Animals}

Thirty-six healthy Babion rabbits of age ranged from 2.5 to 3 months-old and weighing between 2 and 2.5 kilogram were used in this study. The experiment was performed in compliance with guidelines developed by Faculty of Veterinary Medicine, Zagazig University Egypt, for the ethical conduct of care and use of animals. Animals were equally and randomly assigned into three treatment groups ( $\mathrm{n}=12$ each) according to type of implant: 1) Silicate 45S5 BG,2) PRP gel, and 3) $\mathrm{PRP} /$ silicate 45S5 BG group. Each group was further subdivided into four subgroups ( $\mathrm{n}=3$ each) based on the scheduled euthanasia time points.

\section{Preparation of PRP geL}

In accordance to previously published protocol (Marx et al., 1998), PRP gel preparation was started several minutes before surgery (Figure $1 \mathrm{~A}-\mathrm{C}$ ). Eight milliliters of whole venous blood was freshly drawn from each animal via jugular venipuncture. Blood sample was then gently mixed with anticoagulant citrate dextrose (ACD; Sigma, Germany), and centrifuged at $5600 \mathrm{rpm}$ for 10 minutes at room temperature. After centrifugation, three layers were obtained; 1) upper portion (contained platelets poor plasma, PPP), 2) middle portion or "buffy coat" (contained platelets rich plasma, PRP), and 3) lower portion (contained $\mathrm{RBCs}$ ). To increase harvest of obtained platelets as well as proper separation from RBCs, the upper and middle plasma portions were subjected to second centrifugation step at $2400 \mathrm{rpm}$ for 10 minutes. The supernatant contained PPP was then discarded. For gel formation, approximately $3 \mathrm{ml}$ of PRP (contained platelet concentrate) was mixed with calcium chloride/ bovine thrombin mixture (Sigma, Germany) in a water bath at $37^{\circ} \mathrm{C}$.

\section{FABRICATION OF SILICATE 45S5 BIOACTIVE GLASS}

High-pure $\mathrm{SiO}_{2}, \mathrm{Na}_{2} \mathrm{CO}_{3}, \mathrm{CaCO}_{3}$ and $\mathrm{P}_{2} \mathrm{O}_{5}$ powders were used to fabricate $\mathrm{BG}$ scaffold with composition $45 \mathrm{SiO}_{2}-24.5 \mathrm{CaO}-24.5 \mathrm{Na}_{2} \mathrm{O}-6 \mathrm{P}_{2} \mathrm{O}_{5} \mathrm{~mol} \%$. In brief, powders were weighed, mixed and heat processed in alumina crucibles in an electric furnace for $4 \mathrm{hrs}$ at $1400^{\circ} \mathrm{C}$ with a de-carbonation step $\left(5 \mathrm{hrs}\right.$ at $\left.950^{\circ} \mathrm{C}\right)$. The melt obtained was occasionally swirled to assure homogeneity and attainment of thermal and chemical

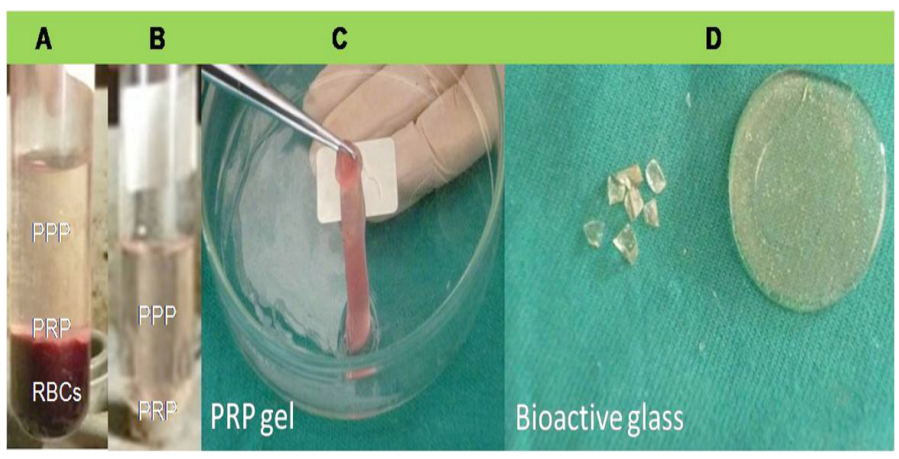

Figure 1: Preparation steps of PRP gel; layers after first (A) and second (B) centrifugation and PRP gel formation (C). 45S5 silicate bioactive glass discs which used as scaffold materials (D).

equilibrium. Once the heat processing was finished, melted glass was poured and pressed to yield disc like shape samples. The glassy discs were annealed at $500^{\circ} \mathrm{C}$ and then allowed to cool slowly to obtain glass ceramic scaffold (Figure 1D). 


\section{Creating Surgical Defect AND BIOMATERIAL IMPLANTATION}

Animals were intramuscularly anesthetized using combination of ketamine hydrochloride $(30 \mathrm{mg} / \mathrm{kg}$; Ketamine $^{\varpi}$, Rota Medica, Germany) and xylazine (3mg/kg; Xyla-ject ${ }^{\oplus}$, Adwia, Egypt). Under complete sterile precautions, a longitudinal skin incision of about 1.5 to $2 \mathrm{~cm}$ long was made at $1 \mathrm{~cm}$ distal to femorotibial joint and over the medial aspect of both right and left tibias. Under constant irrigation with sterile saline solution, $3.5 \mathrm{~mm}$ circular cortical bone defect was created using bone drill with $3.0 \mathrm{~mm}$ bone drill bit and followed by $3.5 \mathrm{~mm}$ surgical tap. Afterwards implants were carefully packed into the right defect while left defect served as a control. Muscles, fascia and skin were separately closed in a classical manner. During postoperative period, animals were allowed to recover before returning back to the animal facility and received antibiotic for three consecutive days.

\section{Macroscopic Examination}

In each group, animals were euthanized at the scheduled time points and defect size measurement was performed. Representative photomicrographs at each time point per each group were also captured.

\section{X-RAY FILMING}

Radiographic evaluation of all examined groups was performed immediately after surgery as well as at 15 , 30, 45 and 60 days post operatively. The settings used were; $40 \mathrm{kV}$ and $300 \mathrm{~mA}$ at $0.1 \mathrm{~s}$. The obtained radiographs were scanned to quantify bone densities using ImageJ software (NIH Image, USA) at all scheduled observation time points.

\section{Histopathologic ASSESSMENT}

Animals ( $\mathrm{n}=3$ per group) were euthanized at 45 and 60 days postoperatively. Collected specimens were fixed in 10\% neutral buffered formalin and de-calcified. Paraffin embedded samples were then serially sectioned (approximately 100 slices with $6 \mu \mathrm{m}$ slice thickness per defect), and stained with hematoxylin and eosin (H\&E) staining method. Finally, sections were dehydrated then covered with mounting medium and cover slip. Photomicrographs were obtained with inverted light microscope.

\section{HISTOMORPHOMETRIC MEASUREMENTS}

H\&E-stained sections of both treated and untreated osseous defects were used for quantification of percent bone formation (mean $\pm \mathrm{SD})$ at three standardized locations within the defect versus the total area defect. All these threshold measurements were performed using Image J software (NIH Image, USA).

\section{STATISTICAL ANALYSIS}

Statistical analyses were performed using GraphPad Prism-4 software (La Jolla, Ca). The obtained data were expressed as mean $\pm \mathrm{SD}$. Differences between groups were analyzed using a one-way ANOVA and Tukey test for post-hoc comparisons. The significance levels were defined at $\mathrm{P}<0.05$.

\section{RESULTS}

\section{Macroscopic ObSERVATION}

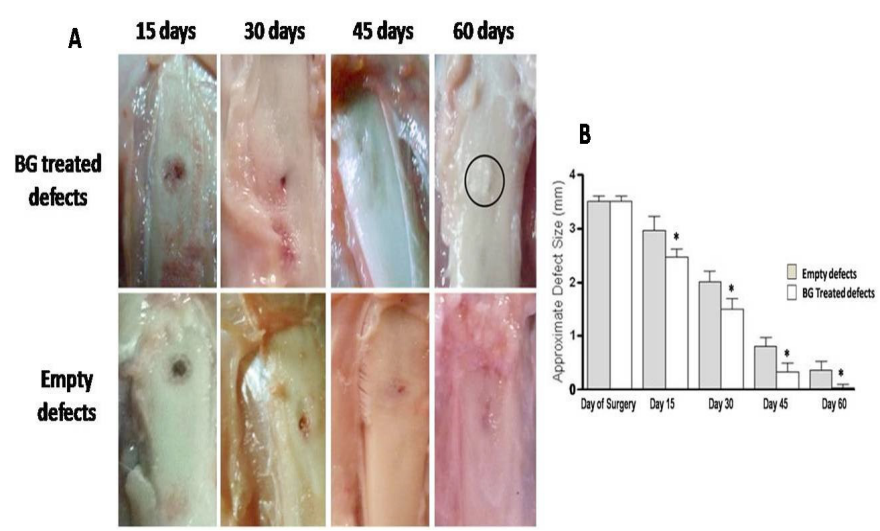

Figure 2: Gross observation of silicate 45S5 BG treated defects shows complete re-buildup by 60 days with a noticeable callus irregularity (circle) (A) with significant decreasing effect on defect size at all-time point $(\mathrm{B}) .{ }^{*} \mathrm{P}<0.05$

Measured values of approximate defect size in all groups are presented in table 1 . BG group showed gradual and significant reducing effect on defect size at each time point $(\mathrm{P}<0.05)$ compared with reference defects (Figure 2A, B). Noticeable re-buildup was recorded at 60 day time period (Figure 2A). As well, an irregularity was clearly felt on the area of healed 
defect. Whereas those of PRP - engrafted group revealed higher significant healing effect only at early
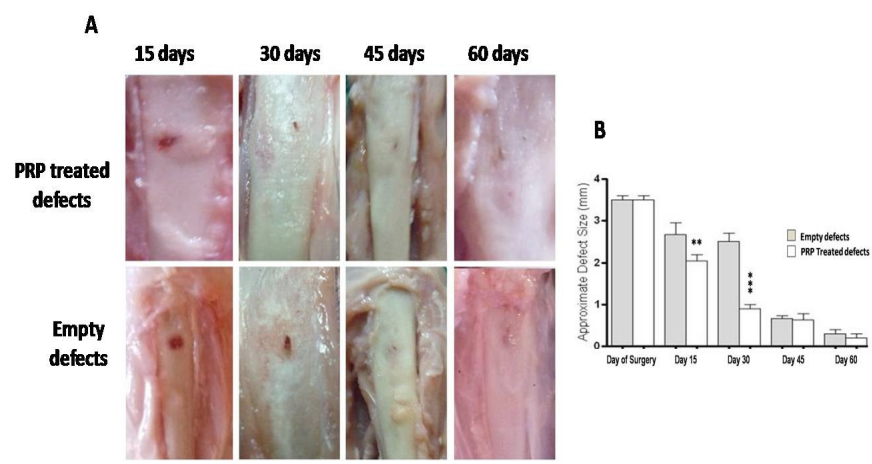

Figure 3: Gross observation of PRP treated defects presents lack of incomplete closure by 60 days (A). However, interestingly, marked significant healing effect only at 15 and 30 days post injury was evident (B). ${ }^{* *} \mathrm{P}<0.01$ and ${ }^{* * *} \mathrm{P}<0.001$

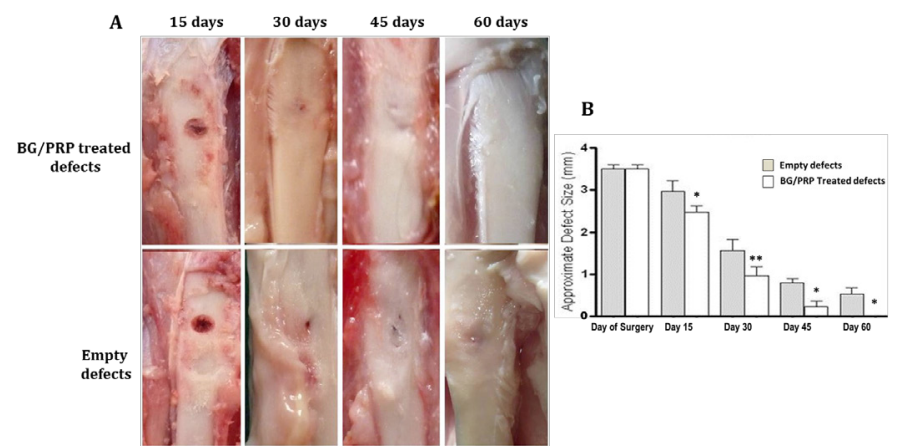

Figure 4: Gross observation of silicate 45S5 BG/ PRP treated defects exhibits complete healing by 60 days with a noticeable smooth callus surface (A) and significant decrease of the defect size at all-time points (B). ${ }^{*} \mathrm{P}<0.05$ and ${ }^{* *} \mathrm{P}<0.01$

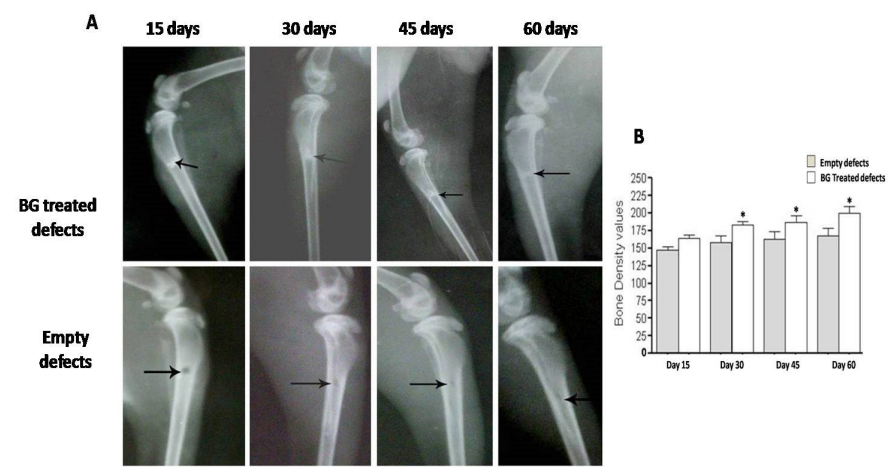

Figure 5: Radiographic evaluation displays complete bony regenerate throughout defects treated with silicate 45S5 BG (A) in addition to significant increase in radiopacity $(\mathrm{B}) .{ }^{*} \mathrm{P}<0.05$

periods; i.e. 15 and 30 days post injury than those of un-grafted defects $(\mathrm{P}<0.01$ and $\mathrm{P}<0.001$, respectively)
(Figure 3B). Following, the degree of healing was not significant at days 45 and 60 follow-up (Fig. 3A, B). Complete reconstruction of defect at day 60 was not observed. Defects engrafted with BG/PRP showed significant difference in defect closure at day 15 postoperatively $(\mathrm{P}<0.05)$ (Fig. 4B). Marked significant decrease of the defect size $(\mathrm{P}<0.01)$ by day 30 post injury was displayed as compared with their reference defects. Unlike untreated defects, at 45 and 60 days, the defects healed significantly $(\mathrm{P}<0.05)$, and were completely closed by 60 days (Fig. 4B). There were no irregularities on area of healed defects (Fig. 4A).

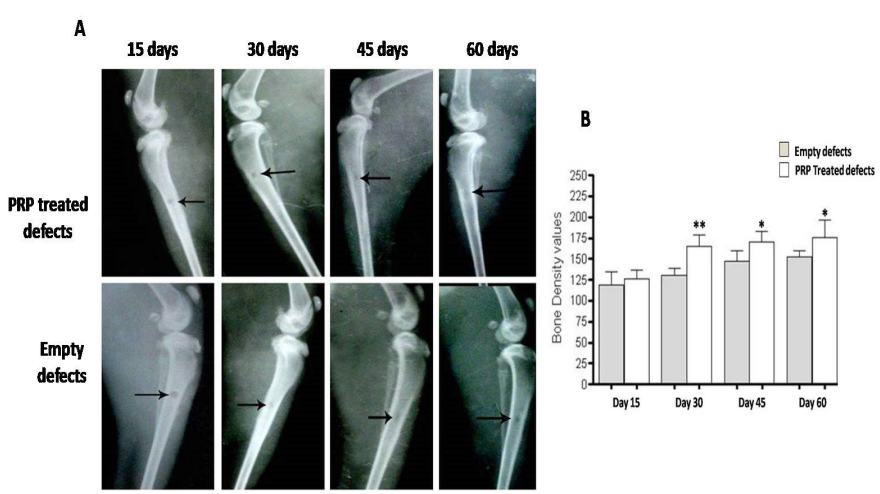

Figure 6: Radiographic evaluation reveals incomplete osseous healing in both PRP- treated and untreated defects (A) with a marked significant increase in radiopacity at 30 days post-injury (B). ${ }^{*} \mathrm{P}<0.05$ and ** $\mathrm{P}<0.01$

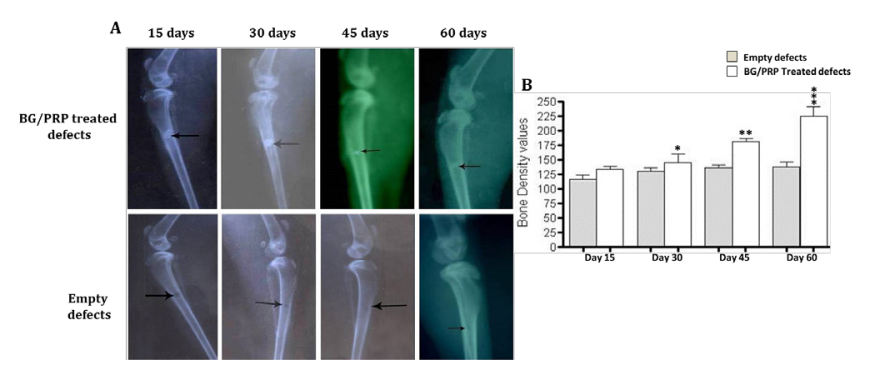

Figure 7: Radiographic evaluation shows complete bony regenerate throughout defects treated with silicate 45S5 BG/PRP (A) in addition to significant increase in radiopacity mainly at 45 and 60 days postoperative (B). ${ }^{*} \mathrm{P}<0.05,{ }^{* *} \mathrm{P}<0.01$ and ${ }^{* * *} \mathrm{P}<0.001$

\section{RADIOGRAPHIC FINDINGS}

In order to verify the gross findings, radiographic imaging and quantification of bone density in the areas of defects were done at the same scheduled time points. Table 2 shows the measured bone mineralization density (radiopacity) data in both treated and 
untreated bone defects. In defects implanted with only BG we found a regular and significant increase in bony regenerate with successful healing of the defect by 60 days after surgery (Figure $5 \mathrm{~A}$ ).

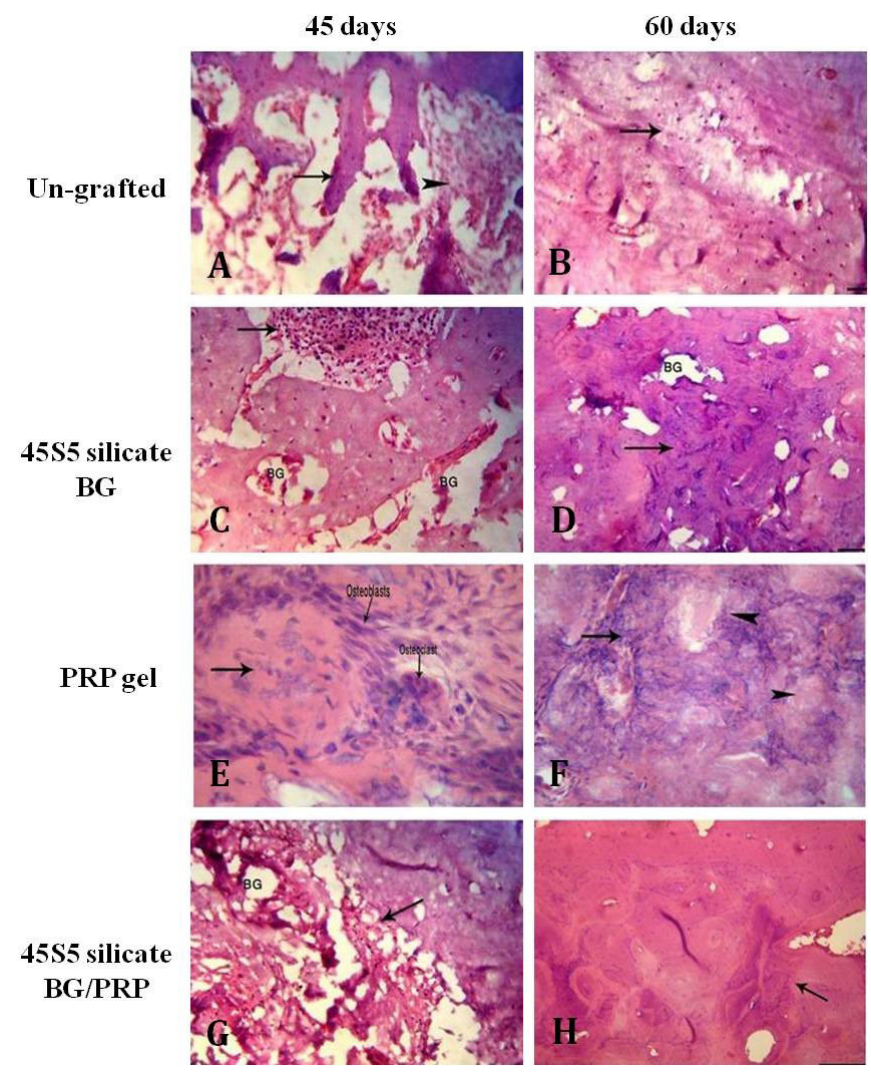

Figure 8: Histological findings of treated and untreated defects after $\mathrm{H} \& \mathrm{E}$ staining. Ungrafted defects shows thin woven bone trabeculae (arrow) with wide intertrabecular spaces containing granulation tissue (arrowhead) at day 45 (A), and incomplete defect fill (arrow) at day 60 (B). Silicate 45S5 BGtreated group displays newly formed bone invading defect center at day 45. Bone marrow is also observed (arrow) (C). Center is completely filled with newly immature woven bone (arrow) at day 60 (D). While in PRP-treated group, no much newly formed bone tissue (arrow) at day 45 is observed (E). Incomplete fill of defect with basophilic mineralized bone (arrow) and remnants of PRP (arrow head) are indicated at day 60. (F), whereas in silicate 45S5 BG/PRP-treated group, the defect is nearly replaced by newly formed osseous tissue containing BG particles (arrow) at day $45(\mathrm{G})$. Complete fill of the bone defect with integrated mature lamellar osteoid tissue is indicated (arrow) at day 60 (H). 20x magnifications

Further, radiopacity (bone density) was increased regularly and significantly at 30,45 and 60 days $(\mathrm{P}<0.05)$ August 2014 | Volume 2 | Issue 8 | Page 428 comparably with control defects (Figure 5B). While in group received $\mathrm{PRP}$, the new osseous formation was accelerated robustly at 30 days $(\mathrm{P}<0.01)$ (Figure 6B), whereas, by 45 and 60 days, the radiopacity increased moderately when compared to control counterparts $(\mathrm{P}<0.05)$ (Figure 6B). Even though, complete defect regeneration was not detected over 60 days healing period (Figure 6A). In third group which received combination of BG and PRP, there was evidence of moderate increasing in the volume of newly formed bone and bone densities at 30 and 45 days post operation $(\mathrm{P}<0.05$ and $\mathrm{P}<0.01$, respectively) (Figure 7A, B). Additionally, slight differences between BG group and $\mathrm{PRP} / \mathrm{BG}$ group could be noted at those time points. By 60 days, we noticed marked increase in radiopacity that was higher than those of empty defects $(\mathrm{P}<0.001)$ (Figure 7A, B).

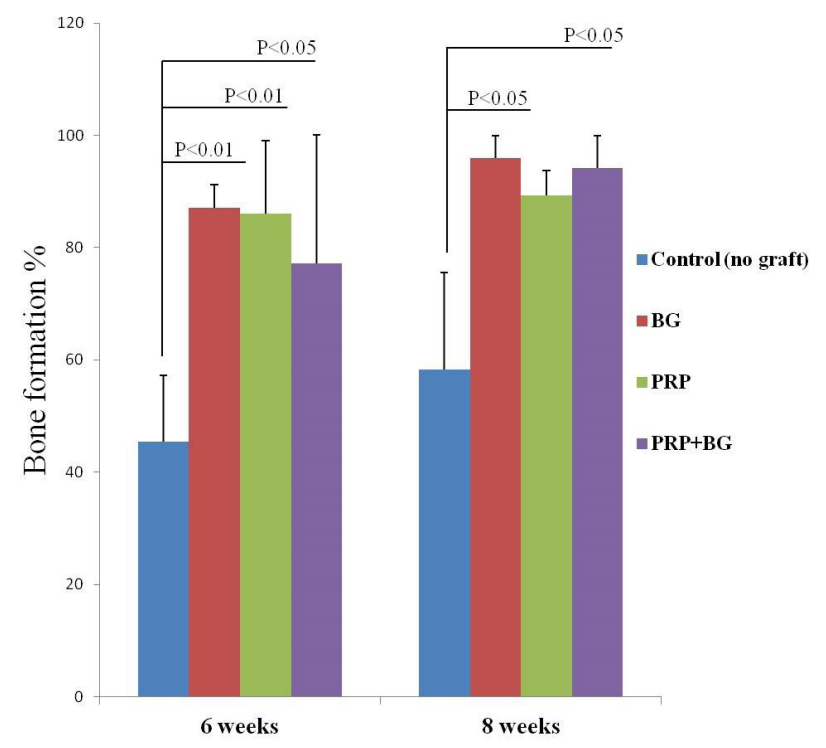

Figure 9: Bar graph presenting the percent bones formation as indicated by H\&E. Note increasing bone formation over time except in PRP by 8 weeks.

\section{Histological REsults}

Generally here we focused on only three descriptive criteria to describe our histological findings; 1) approximate proportion of intertrabecular spaces (cavitation), 2) amount of the newly formed osseous tissue filling defect, and 3) replacement rates of biomaterial with bone tissues, in addition to quantitative histomorphometric analysis. An increasing of bone formation ratio was found in all treated groups at 6 and 8 weeks by histomorphometric measurements except untreated group and PRP by 8 weeks (table 3 and Figure 9). In un-grafted defects, at $45^{\text {th }}$ day, thin wo- 
Table 1: Mean \pm SD values of the approximate defect size of both grafted right $(\mathrm{R})$ and ungrafted left (L) surgically created osseous defects. DOP: day of operation, PO: post-operation.

\begin{tabular}{lllllll} 
Groups & & $\begin{array}{l}\text { Day-0 } \\
\text { DOP }\end{array}$ & $\begin{array}{l}\text { Day-15 } \\
\text { PO }\end{array}$ & $\begin{array}{l}\text { Day-30 } \\
\text { PO }\end{array}$ & $\begin{array}{l}\text { Day-45 } \\
\text { PO }\end{array}$ & $\begin{array}{l}\text { Day-60 } \\
\text { PO }\end{array}$ \\
\hline Silicate-45S5 BG & L & $3.5 \pm 0.10$ & $2.97 \pm 0.27$ & $2.10 \pm 0.20$ & $0.97 \pm 0.25$ & $0.37 \pm 0.15$ \\
& R & $3.5 \pm 0.10$ & $2.47 \pm 0.15$ & $1.50 \pm 0.20$ & $0.34 \pm 0.15$ & $0.03 \pm 0.06$ \\
PRP & L & $3.5 \pm 0.10$ & $2.97 \pm 0.25$ & $2.50 \pm 0.21$ & $0.67 \pm 0.06$ & $0.30 \pm 0.10$ \\
& R & $3.5 \pm 0.10$ & $2.04 \pm 0.15$ & $0.90 \pm 0.10$ & $0.63 \pm 0.15$ & $0.20 \pm 0.10$ \\
$\begin{array}{l}\text { PRP + Sili- } \\
\text { cate-45S5 BG }\end{array}$ & $\mathrm{L}$ & $3.5 \pm 0.10$ & $2.95 \pm 0.26$ & $1.77 \pm 0.15$ & $0.73 \pm 0.06$ & $0.30 \pm 0.11$ \\
& $\mathrm{R}$ & $3.5 \pm 0.10$ & $2.46 \pm 0.14$ & $0.90 \pm 0.10$ & $0.50 \pm 0.20$ & $0.00 \pm 0.00$
\end{tabular}

Table 2: Mean \pm SD values of the bone density/radiopacity of both grafted right $(\mathrm{R})$ and ungrafted left $(\mathrm{L})$ surgically created osseous defects at different time points. DOP: day of operation, PO: post-operation.

\begin{tabular}{|c|c|c|c|c|c|}
\hline Groups & & $\begin{array}{l}\text { Day-15 } \\
\text { PO }\end{array}$ & $\begin{array}{l}\text { Day-30 } \\
\text { PO }\end{array}$ & $\begin{array}{l}\text { Day-45 } \\
\text { PO }\end{array}$ & $\begin{array}{l}\text { Day-60 } \\
\text { PO }\end{array}$ \\
\hline \multirow{2}{*}{$\begin{array}{l}\text { Silicate-45S5 } \\
\text { BG }\end{array}$} & $\mathrm{L}$ & $147.687 \pm 3.636$ & $158.089 \pm 9.023$ & $162.507 \pm 10.946$ & $167.092 \pm 10.924$ \\
\hline & $\mathrm{R}$ & $163.692 \pm 4.836$ & $182.733 \pm 4.729$ & $187.096 \pm 9.303$ & $200.205 \pm 8.671$ \\
\hline \multirow[t]{2}{*}{ PRP } & $\mathrm{L}$ & $118.489 \pm 15.808$ & $130.079 \pm 8.835$ & $147.341 \pm 12.25$ & $152.335 \pm 7.424$ \\
\hline & $\mathrm{R}$ & $125.62 \pm 10.451$ & $165.295 \pm 13.326$ & $170.663 \pm 11.587$ & $175.58 \pm 20.482$ \\
\hline \multirow{2}{*}{$\begin{array}{l}\mathrm{PRP}+\mathrm{Sili}^{-} \\
\text {cate-45S5 BG }\end{array}$} & $\mathrm{L}$ & $115.943 \pm 8.206$ & $130.274 \pm 6.554$ & $136.659 \pm 4.463$ & $137.042 \pm 9.05$ \\
\hline & $\mathrm{R}$ & $133.154 \pm 5.702$ & $144.952 \pm 15.083$ & $180.769 \pm 6.031$ & $225.159 \pm 15.806$ \\
\hline
\end{tabular}

Table 3: The percent bone formation $($ mean \pm SD) as detected by H\&E 6 and 8 weeks after. PO: post-operation.

\begin{tabular}{lll} 
Groups & $\mathbf{6}$ weeks PO & $\mathbf{8}$ weeks PO \\
\hline Control (no graft) & $45.406 \pm 11.798$ & $58.244 \pm 17.391$ \\
\hline Silicate-45S5 BG & $87.117 \pm 4.104$ & $95.946 \pm 4.054$ \\
PRP & $86.108 \pm 12.887$ & $89.297 \pm 4.409$ \\
PRP + Silicate-45S5 BG & $77.207 \pm 22.807$ & $94.189 \pm 5.7205$ \\
\hline
\end{tabular}

ven bone with irregular intertrabecular spaces were noted (Figure 8A).

At $60^{\text {th }}$ day, the center of the defect was incompletely filled with immature woven newly formed bone tissue August 2014 | Volume 2 | Issue 8 | Page 429 indicated by presence of small empty cavitation in the central defect core (Figure 8B). In BG group, at $45^{\text {th }}$ day, newly formed bone was noted highly invading the center of the defect. Layers of newly formed bone on the borders of fragmented BG molecules were also 
found (Figure $8 \mathrm{C}$ ). At $60^{\text {th }}$ day, fragmented biomaterials were evident and center was even completely filled with newly formed bone, mainly of immature woven bone (Figure $8 \mathrm{D}$ ). In PRP group, at $45^{\text {th }}$ day, there was no much newly formed bony tissue in the defect (Figure $8 \mathrm{E}$ ). At $60^{\text {th }}$ day, incomplete defect closure with PRP remnants were identified (Figure 8F). While in $\mathrm{BG} / \mathrm{PRP}$ group, at 45 day, newly formed bone tissue containing bioactive granules (BG) replaced the cavity without evidence of connective tissue (Figure 8G). At $60^{\text {th }}$ day, the defect was entirely filled with new osteoid tissue of mainly mature lamellar bone. Remodeling of newly formed bone with absence of $\mathrm{BG}$ granules was observed (Figure 8H).

\section{DISCUSSION}

It has been a great challenge to heal large bone defects properly using clinically appropriate and safe biomaterials. Thus, the present study was designed for the first time to examine the efficacy of silicate $45 \mathrm{~S} 5 \mathrm{BG}$ in combination with PRP for the repair of long bone defect. Herein, PRP did not improve to some what extent bone healing by 60 days. However, interestingly, marked significant healing effect of PRP was noted only at early period of the study (i.e., 30 days post injury; $\mathrm{P}<0.01)$ than those of un-grafted defects. In parallel, other clinical applications have shown that PRP has a positive effect only at early phase of bone healing (Yilmaz et al., 2013). One explanation for this finding could be attributed to the platelets release growth factors immediately at the area, which work only for a period of 7 to 10 days (Marx et al., 1998). Perhaps for this reason some authors have found a significant result of PRP at the initial periods, with no differences at completion of the repair process (Zechner et al., 2003).

In contrary, basic research approves the potentiality of $\mathrm{PRP}$ to enhance bone regeneration when used alone (Gandhi et al., 2006). However, others could not confirm enhancement effect of PRP on bone healing when combined with other implants (Mooren et al., 2010). Additionally, more recent published study stated that PRP alone or combined with bovine inorganic bone had not exert any significant effect on bone healing of bone cavities created in dogs mandibles (Bassi and Carvalho, 2011). BG type, namely 45S5 $\mathrm{BG}$, was chosen to be used here since it has much more osteostimulatory effect and osteoconductive properties (Schepers and Ducheyne, 1997). The bioactivity of BG scaffolds is due to their ability to form silica-phosphate-calcium rich surface layer through a series of hydro-reactions when it becomes in contact with body fluid (Hench, 1998). With time, this layer acts as a matrix and plays a valuable role in adhesion and proliferation of osteogenic cells to form new osseous tissue (Marelli et al., 2011).

In the present study, silicate BG showed a significant defect reconstruction when compared to control defects over the course of 60 days post-injury, as verified by macroscopic, radiologic and histological examination as well as bone density analysis. These findings are in agreement with previous studies demonstrated that BG has been beneficial to repair periodontal osseous lesions (Nevins et al., 2000) and intra-bony defects (Satyanarayana et al., 2012). These findings could be attributed to BG stimulates bone marrow mesenchymal stem cells to differentiate into osteoblast-like cells with a higher mineralized tissue formation (Bosetti and Cannas, 2005). Furthermore, herein, there was no significant statistical difference between silicate BG and $\mathrm{PRP} / \mathrm{BG}$ in bone healing after 60 days. Histologically, however, the healing induced by PRP/BG was better than that induced by $\mathrm{BG}$ alone, as indicated by formation of more mature osteoid tissue. Consistently, more recent studies have been declared that the use of PRP in association with borate BG improved bone healing compared with BG alone (Zhang et al., 2011).

\section{CONCLUSION}

PRP alone does not provide marked significant improvement in osseous defect healing at 60 days post-injury. Further studies therefore are required to better define their effect during process of bone repair. However, silicate 45S5 BG improves bone healing particularly when engrafted with PRP.

\section{ACKNOWLEDGEMENTS}

The authors would like to thank Dr. Hani Kamal; Department of Physics, Faculty of Science, Mansura Uni. for excellent assistance in preparation of BG. Also thanks to Prof. Dr. Mohamed Hammed; Department of Pathology, Faculty of Vet. Med., Zagazig Uni., for his appreciated role in interpretation of the histopathological findings. 


\section{CONFLICTS OF INTEREST}

The authors indicate no potential conflicts of interest.

\section{REFERENCES}

- Abdollahi S, Ma C, Cerruti M (2013). Surface transformations of Bioglass 45S5 during scaffold synthesis for bone tissue engineering. Langmuir. 5: 1466-74.

- Almaiman M, Al-Bargi H, Manson P (2013). Complication of anterior iliac bone graft harvesting in 372 adult patients from may 2006 to may 2011 and a literature review. Craniomaxillofac Trauma Reconstr. 6: 257-66.

- Bassi A, Carvalho P (2011). Repair of bone cavities in dog's mandible filled with inorganic bovine bone and bioactive glass associated with platelet rich plasma. Braz Dent J. 22: 14-20.

- Bosetti M, Cannas M (2005). The effect of bioactive glasses on bone marrow stromal cells differentiation. Biomaterials. 26: 3873-3879.

- Carvalho M, Suaid F, Santamaria M, Casati M, Nociti F, Sallum A, Sallum E (2011). Platelet-rich plasma plus bioactive glass in the treatment of intra-bony defects: a study in dogs. J Appl Oral Sci. 19: 82-89.

- Demir B, Sengun D, Berberoglu A (2007). Clinical evaluation of platelet-rich plasma and bioactive glass in the treatment of intra-bony defects. J Clin Periodontol. 34: 709-715.

- Fang T, Nacamuli R, Song H, Fong K, Shi Y, Longaker $M$ (2006). Guided tissue regeneration enhances bone formation in a rat model of failed osteogenesis. Plast Reconstr Surg. 117: 1177-1185.

- Gandhi A, Doumas C, O'Connor J, Parsons J, Lin S (2006). The effects of local platelet rich plasma delivery on diabetic fracture healing. Bone. 38: 540-546.

- Hench L (1998). Bioactive materials: the potential for tissue regeneration. J Biomed Mater Res. 41: 511-518.

- Lieberman J, Daluiski A, Einhorn T (2002). The role of growth factors in the repair of bone. Biology and clinical applications. J Bone Joint Surg Am. 84-A: 1032-1044.

- Marelli B, Ghezzi C, Mohn D, Stark W, Barralet J, Boccaccini A, Nazhat S (2011). Accelerated mineralization of dense collagen-nano bioactive glass hybrid gels increases scaffold stiffness and regulates osteoblastic function. Biomaterials. 32: 8915-8926.

- Marx R, Carlson E, Eichstaedt R, Schimmele S, Strauss J, Georgeff K (1998). Platelet-rich plasma: Growth factor enhancement for bone grafts. Oral Surg Oral Med Oral Pathol Oral Radiol Endod. 85: 638-646.

- Mooren R, Dankers A, Merkx M, Bronkhorst E, Jansen J, Stoelinga P (2010). The effect of platelet-rich plasma on early and late bone healing using a mixture of particulate autogenous cancellous bone and Bio-Oss: an experimental study in goats. Int J Oral Maxillofac Surg. 39: 371-378.

- Nevins M, Camelo M, Nevins M, King C, Oringer R, Schenk R, Fiorellini J (2000). Human histologic evaluation of bioactive ceramic in the treatment of periodontal osseous defects. Int J Periodontics Restorative Dent. 20: 458-467.

- Penteado L, Colombo C, Penteado R, Assis A, Gurgel B (2013). Evaluation of bioactive glass and plateletrich plasma for bone healing in rabbit calvarial defects. Journal of Oral Science. 55: 225-232.

- Rivadeneira J, Carina M, Boccaccini R, Gorustovich A (2013). In vitro antistaphylococcal effects of a novel 45S5 bioglass/agar-gelatin biocomposite films. J Appl Microbiol. 115: 604-12.

- Sanchez A, Sheridan P, Kupp L (2003). Is platelet-rich plasma the perfect enhancement factor? A current review. Int J Oral Maxillofac Implants. 18: 93-103.

- Satyanarayana K, Anuradha B, Srikanth G, Chandra P, Anupama T, Durga P (2012). Clinical Evaluation of Intrabony Defects in Localized Aggressive Periodontitis Patients with and without Bioglass- An In-vivo Study. Kathmandu Univ Med J (KUMJ). 10: 11-15.

- Schepers E, Ducheyne P (1997). Bioactive glass particles of narrow size range for the treatment of oral bone defects: a 1-24 month experiment with several materials and particle sizes and size ranges. J Oral Rehabil. 24: 171-181.

- Trindade-Suedam I, de Morais J, Faeda R, Leite F, Tosoni G, Neto C, Marcantonio E, Scaf G, (2010). Bioglass associated with leukocyte-poor platelet-rich plasma in the rabbit maxillary sinus: histomorphometric, densitometric, and fractal analysis. J Oral Implantol. 36: 333-343.

- Vogel M, Voigt C, Gross U, Muller-Mai C (2001). In vivo comparison of bioactive glass particles in rabbits. Biomaterials. 22: 357-362.

- Wang H, Avila G (2007). Platelet rich plasma: myth or reality? Eur J Dent. 1: 192-194.

- Wheeler D, Eschbach E, Hoellrich R, Montfort M, Chamberland D (2000). Assessment of resorbable bioactive material for grafting of critical-size cancellous defects. J Orthop Res. 18: 140-148.

- Yilmaz S, Karaca E, Ipci S, Cakar G, Kuru B, Kullu S, Horwitz J (2013). Radiographic and histologic evaluation of platelet-rich plasma and bovine-derived xenograft combination in bilateral sinus augmentation procedure. Platelets. 24: 308-315.

- Zechner W, Tangl S, Tepper G, Furst G, Bernhart T, Haas R, Mailath G, Watzek G (2003). Influence of platelet-rich plasma on osseous healing of dental implants: a histologic and histomorphometric study in 
minipigs. Int J Oral Maxillofac Implants. 18: 15-22.

- Zhang Y,Wang G, Sun Y,Zhang C (2011). Combination of platelet-rich plasma with degradable bioactive borate glass for segmental bone defect repair. Acta Orthop Belg. 77: 110-115. 